\title{
A Numerical Model for Studying the Thermal Denaturation-Aggregation of Whey Proteins under Continuous Thermal Processing
}

\author{
Artemio Plana-Fattori ${ }^{a^{*}}$, Christophe Doursat ${ }^{\mathrm{a}}$, Alienor Coutouly ${ }^{\mathrm{b}}$, Alain \\ RiAublanc $^{\mathrm{b}}$, AND DENis FlicK ${ }^{\mathrm{a}}$ \\ ${ }^{a}$ Université Paris-Saclay, INRAE, AgroParisTech, UMR SayFood, 91300, Massy, France \\ ${ }^{\mathrm{b}}$ UR Biopolymères Interactions Assemblages, INRA, 44316 Nantes, France \\ ${ }^{*}$ Corresponding author \\ artemio.planafattori@agroparistech.fr \\ TEL: +33.1.44.08.86.84
}

Received: 31 August 2018; Published online: 18 January 2020

Invited paper from the 2nd edition of the International School on Modeling and Simulation in Food and Bio Processes

\begin{abstract}
A computational fluid dynamics model was designed to study the problem of thermal processing of a liquid food product containing whey proteins within a heat exchanger consisting of heating, holding and cooling tubular sections. This physical problem is associated with strong coupling between the phenomena of fluid flow, heat transfer, and thermal denaturation-aggregation of whey proteins. Our primary objective was to investigate the two-way coupling between these phenomena within the heat exchanger. This was carried out by analyzing the model predictions of velocity, temperature and product properties at both axial and radial directions. Attention was focussed on the whey proteins present in a cream cheese formulation. The thermal denaturation-aggregation kinetics was supposed to follow that of the beta-lacto-globulin, which plays a major role in fouling when milk derivatives are submitted to thermal processing in heat exchangers. Model predictions demonstrated that the apparent viscosity of the liquid product exhibited a complex behavior along the processing unit: in addition to its dependence on local temperature, it was affected by the local degree of denaturation of whey proteins - and hence on the product history previous to this position in the heat exchanger. The numerical model was structured into a sequence of computational domains; its versatility was illustrated by changing the length of the holding section and then assessing the impact on the final degree of denaturation of the whey proteins present in the liquid product.
\end{abstract}

Keywords: Computational Fluid Dynamics (CFD); Thermal denaturation-aggregation; Whey proteins; Beta-lacto-globulin; Heat exchanger

\section{Introduction}

Heat treatment of foods need to be optimized to promote beneficial effects and to counteract undesired effects (van Boekel et al., 2010). The advantages of using continuous processing units for fluid foods, instead of batch processing, are the increase in production rate, the reduction in energy consumption and the improvement on both sensorial and nutritional attributes of the product (Ramaswamy, Abdelrahim, Simpson, \& Smith, 1995). Looking for reproducible manufacturing of fluid foods, it is necessary to understand a) the mechanisms driving the physicochemi- 
cal characteristics of ingredients, and b) the interactions occurring between ingredients under thermo-mechanical treatment. In other words, it is necessary to know how the liquid product is transformed along the processing pathway. The thermal continuous processing of liquid food products is very often conducted by employing heat exchangers whose basic elements are the heater, the holder and the cooler. The liquid product is first exposed to heating up to a target temperature, whose value depends on the changes desired in the physicochemical structure of ingredients present in the liquid product: denaturation-aggregation of whey proteins, swelling of starch granules, etc. Along the holder, the liquid product is supposed to flow at the target temperature under thermally-insulated conditions in order to progressively reach the target state of transformation. Finally, the liquid product is exposed to quick cooling in order to stop the changes affecting ingredients as well as the interactions among them. In summary, the final structure of the liquid product can depend on a number of factors, since the concentration of raw ingredients up to the operating conditions that are chosen in running the processing unit.

Modelling can reduce the amount of experimentation which is required in designing food products, processes and equipments; further, physicsbased modelling provides a level of insight that is usually not possible experimentally (Datta, 2008). There are problems in which the evolution of the liquid has negligible impact on the phenomena of heat transfer in fluids. Indeed, in the case of the thermal inactivation of microorganisms and enzymes in food liquids, it seems sufficient to estimate the minimal thermal inactivation, which can be computed from the minimum residence time obtained after assuming plug-flow (Aguiar \& Gut, 2014). The study of liquid products becomes very challenging from the modelling perspective when there is two-way coupling between phenomena of fluid flow and heat transfer in the processing unit. Such a coupling is relevant in the dairy industry, because it is associated with the formation of deposits of transformed product onto the heat transfer surfaces (fouling which can reduce heat transfer and add resistance to fluid flow (Goode, Asteriadou, Robbins, \& Fryer, 2013; Khaldi et al.,
2018; Li, Singh, \& Lee, 2004). In such a coupled problem, thermal denaturation-aggregation of proteins can affect product rheology, which in turn drives the velocity field through the processing unit. On the other hand, fluid flow influences the temperature field and hence the denaturation-aggregation kinetics rate. Such a situation is clearly more complex that the problem of heat transfer in non-Newtonian fluids whose transport properties depend on temperature only (Chhabra, 1999, see for instance the review by).

Over the past 150 years, some 80 particular solutions have been found for the system of nonlinear partial differential equations which describe the conservation of mass, momentum and energy for viscous flows. Each of these solutions satisfy the complete equations for some special geometry; as expected, almost all the known particular solutions are appropriate for incompressible Newtonian flow with constant transport properties (White \& Corfield, 2006). Much effort has been devoted over decades to the theoretical study of temperature profiles under forced-convection inside heat-conducting tubular sections, including non-Newtonian flows (Bird, Stewart, \& Lightfoot, 2007). Solutions have been reached a) by restricting the attention on the thermal entrance region with a fully developed laminar velocity profile, and b) by neglecting either the heat generation by viscous dissipation or the axial heat conduction in the fluid (Luna, Méndez, \& Treviño, 2002). The non-linear and coupled nature of the conservation equations preclude the possibility of analytical results; numerical solutions are sought, even for as simple a situation as that of laminar flow in a circular tube (Chhabra, 1999). Numerical modelling is clearly required to solve problems related to liquid products whose transport properties evolve with thermal denaturation-aggregation of whey proteins.

A numerical model was implemented to solve the coupled problem of fluid flow, heat transfer, and thermal denaturation-aggregation of whey proteins under realistic conditions. The present study discusses the evolution of the cream cheese formulation of Coutouly, Riaublanc, Axelos, and Gaucher (2014) inside the different tubular sections of a processing pilot unit. Our primary 
objective was to investigate the two-way coupling between those phenomena; in addition, the model was employed as a tool for virtual experiments, predicting the final transformation state of the liquid product under conditions which were not considered in the implementation of the model.

\section{Coupled physical problem}

Steady-state conditions were considered, on one hand because their industrial interest, on the other hand because all the experimental data available to this study were obtained under such conditions. Assuming incompressible fluid, the conservation equations for mass, momentum and energy are expressed as (Bird et al., 2007):

$$
\begin{gathered}
\vec{\nabla} \cdot \vec{u}=0 \\
\rho(\vec{u} \cdot \vec{\nabla}) \vec{u}=\vec{\nabla} \cdot\left(-p \vec{I}+\eta\left(\vec{\nabla} \vec{u}+(\vec{\nabla} \vec{u})^{T}\right)\right) \\
\rho C p(\vec{u} \cdot \vec{\nabla}) T=\vec{\nabla} \cdot(\lambda \vec{\nabla} T)
\end{gathered}
$$

where $\vec{u}$ is the velocity vector (magnitude in $\mathrm{m} / \mathrm{s}), p$ the pressure $(\mathrm{Pa})$, and $T$ the temperature $(\mathrm{K}) ; \rho$ is the liquid product density $\left(\mathrm{kg} \cdot \mathrm{m}^{-3}\right), \eta$ its apparent viscosity (Pa.s), $C p$ its specific heat capacity $\left(\mathrm{J}_{\mathrm{kg}} \mathrm{kg}^{-1} \cdot \mathrm{K}^{-1}\right)$, and $\lambda$ its thermal conductivity $\left(\mathrm{W} \cdot \mathrm{m}^{-1} \cdot \mathrm{K}^{-1}\right)$.

Beta-lacto-globulin is the major whey protein of mature bovine milk (Swaisgood, 1995). In the context of thermal processing of milk derivatives in heat exchangers, the beta-lacto-globulin plays a major role in the deposition mechanism for fouling at temperatures between 75 and 110 ${ }^{\circ} \mathrm{C}$ (Lalande, Tissier, \& Corrieu, 1985). Hence, the thermal denaturation-aggregation behaviour exhibited by the beta-lacto-globulin was a good candidate for the behaviour followed by the whey proteins present in the liquid product studied. The thermal denaturation-aggregation of betalacto-globulin includes: a) the dissociation of native dimers, when the temperature increases above $40{ }^{\circ} \mathrm{C}$; b) the unfolding of native monomers and the formation of a thermally-induced molten globule state, when the temperature increases above $60{ }^{\circ} \mathrm{C}$; and $\mathrm{c}$ ) depending on temperature and shear rate conditions, the occurrence of irreversible intra-molecular interactions allowing the formation of aggregates. As a result, the concentration of native proteins remaining in the liquid product, $C\left(\mathrm{~kg} . \mathrm{m}^{-3}\right)$, progressively decreases along the thermal treatment. Such a tendency has been represented through the reaction kinetics:

$$
\frac{d C}{d t}=-k_{m} C^{m}
$$

where $k_{m}$ is the kinetics rate $\left(\mathrm{s}^{-1} \cdot\left(\mathrm{kg} \cdot \mathrm{m}^{-3}\right)^{-m+1}\right)$. The reaction order $m$ expresses the complexity of underlying mechanisms; in the case of the denaturation of beta-lacto-globulin, it usually takes values between 1 and 2, more commonly 1.5 (Tolkach \& Kulozik, 2007).

Looking for the solution of the coupled problem of fluid flow, heat transfer and thermal denaturation-aggregation of whey proteins under stationary conditions, equation (4) can be written as a convection-reaction-diffusion equation:

$$
\vec{u} \cdot \vec{\nabla} C=-k_{m} C^{m}+\vec{\nabla} \cdot\left(d_{S} \vec{\nabla} C\right)
$$

where $d_{S}$ is the diffusion coefficient $\left(\mathrm{m}^{2} \cdot \mathrm{s}^{-1}\right)$ for the whey proteins in the liquid product.

Actually, the temperature dependence of the kinetics rate $k_{m}$ for denaturation-aggregation of beta-lacto-globulin exhibits a transition between two thermal regimes near $90{ }^{\circ} \mathrm{C}$ (Lyster, 1970). On one hand, at temperatures lower than that transition, the partial unfolding of monomers is slower than their aggregation, and the denaturation-aggregation kinetics becomes limited by the unfolding sub-reaction; on the other hand, at temperatures higher than that transition, the aggregation of thermally-induced molten globules is slower than their formation, and the denaturation-aggregation kinetics becomes limited by the aggregation process (Tolkach \& Kulozik, 2007). Modelling the double regime for the temperature dependence of $k_{m}$ with the help of few parameters constitutes a challenging task (Petit, Herbig, Moreau, \& Delaplace, 2011).

The approach proposed by Tolkach and $\mathrm{Ku}$ lozik (2007) is hereafter assumed for representing the temperature dependence of the denaturationaggregation of beta-lacto-globulin. Following those authors, the kinetics rate $k_{m}$ in equation 
(4) is expressed as

$$
k_{m}=\alpha^{m} k_{a g g}
$$

where $\alpha$ is the degree of unfolding, defined as the mass fraction of unfolded proteins in the liquid product, and calculated from the kinetics rates for unfolding and aggregation:

$$
\alpha=e^{\left(\frac{\ln \left(k_{u n f}\right)-\ln \left(k_{a g g}\right)}{m}\right)}
$$

Both kinetics rates are, in turn, expressed through Arrhenius equations:

$$
\begin{gathered}
\ln \left(k_{u n f}\right)=\ln \left(k_{u n f}^{0}\right)-E_{A, u n f} / R T \\
\ln \left(k_{a g g}\right)=\ln \left(k_{a g g}^{0}\right)-E_{A, a g g} / R T
\end{gathered}
$$

where $k_{u n f}^{0}$ and $k_{a g g}^{0}$ are the frequency factors $\left(\mathrm{s}^{-1} \cdot\left(\mathrm{kg} \cdot \mathrm{m}^{-3}\right)^{-m+1}\right)$ for unfolding and aggregation, $E_{A, u n f}$ and $E_{A, a g g}$ the corresponding energies of activation (J.mol ${ }^{-1}$ ), and $R$ the universal gas constant $\left(\mathrm{J} . \mathrm{mol}^{-1} \cdot \mathrm{K}^{-1}\right)$. The following values are considered: $k_{u n f}^{0}=98.9, k_{a g g}^{0}=21.7$, $E_{A, \text { unf }}=313.9 \cdot 10^{3}{\mathrm{~J} . \mathrm{mol}^{-1}}$, and $E_{A, a g g}=$ $80.8 \cdot 10^{3}{\mathrm{~J} . \mathrm{mol}^{-1}}^{-1}$ Petit et al., 2011; Tolkach \& Kulozik, 2007).

\section{Experimental work}

The liquid food product of interest is the cream cheese model studied by Coutouly et al. (2014). The product had $40 \% \mathrm{w} / \mathrm{w}$ dry matter, including $33.1 \%$ of fat, $3.5 \%$ of caseins, $0.5 \%$ of whey proteins, $2 \%$ of lactose, and $0.8 \%$ of sodium chloride.

The experimental setup was an Armfield FT174X ultra high temperature laboratory scale plant (Armfield Ltd., Ringwood, United Kingdom). Here the attention is focused on the heater, the holder, and the cooler elements of that processing unit (see Figure 1). The heater and the cooler were both constituted of a sequence of eight tubular sections, successively separated by $180^{\circ}$ short curved sections (bends); the holding section was a helical configuration of large curvature compared to the tube diameter. All the sections and tubes have a radius of $4 \mathrm{~mm}$; the heating and cooling sections are $38 \mathrm{~cm}$ long; the liquid product's pathway has a length of about $4.26 \mathrm{~m}$ in the holding section, and about $16 \mathrm{~cm}$ in the bends. The thermal evolution of the liquid product was studied by running the heat exchanger under stationary conditions. Upstream to the heater, the liquid product was pre-heated up to about $40{ }^{\circ} \mathrm{C}$. Along the heater, the product was submitted to indirect heating from the condensation of water vapour on the outer surface of the heating sections, and warmed up to the prescribed holding temperature. Along the cooler, the product was subjected to counterflow cooling, reaching a temperature of about 40 ${ }^{\circ} \mathrm{C}$ at the heat exchanger outlet. The product temperature was recorded at selected positions of the heat exchanger (Figure 1). Heat treatments associated with increasing severity were considered; the weakest was associated with a holding temperature of $72{ }^{\circ} \mathrm{C}$ and to a holding time of $20 \mathrm{~s}$, whereas the strongest was associated with a holding temperature of $94{ }^{\circ} \mathrm{C}$ and to a holding time of $40 \mathrm{~s}$. After each treatment, the transformation state of the liquid product was characterized by its denaturation ratio:

$$
\delta_{\text {outlet }}=1-C_{\text {outlet }} / C_{\text {inlet }}
$$

where $C_{\text {outlet }}$ and $C_{\text {inlet }}$ indicate the concentration of native proteins in the product at the heat exchanger inlet and at its outlet, respectively. The concentration of native proteins was obtained from measurements of nitrogen content, by assuming that all the denaturated-aggregated whey proteins were insoluble at $\mathrm{pH}$ 4.6. After selected heat treatments, the rheological behavior of the liquid product was characterized under decreasing shear rate at 30 and $50{ }^{\circ} \mathrm{C}$, using a temperature-controlled rotational rheometer with double Couette geometry. Coutouly et al. (2014) provided additional information about this liquid product and the experimental methods employed in studying it.

Table 1 summarizes the available experimental results. The same initial sample of liquid product was submitted to three different heat treatments (experiments \#1, \#2 and \#3); two other samples were submitted to the strongest heat treatment only (experiments \#4 and \#5). Measurements of apparent viscosity of the liquid product after experiments \#1, \#2 and \#3 are employed in representing its rheological behavior (see 3.1); temperature and product transformation data obtained from these three experiments were em- 


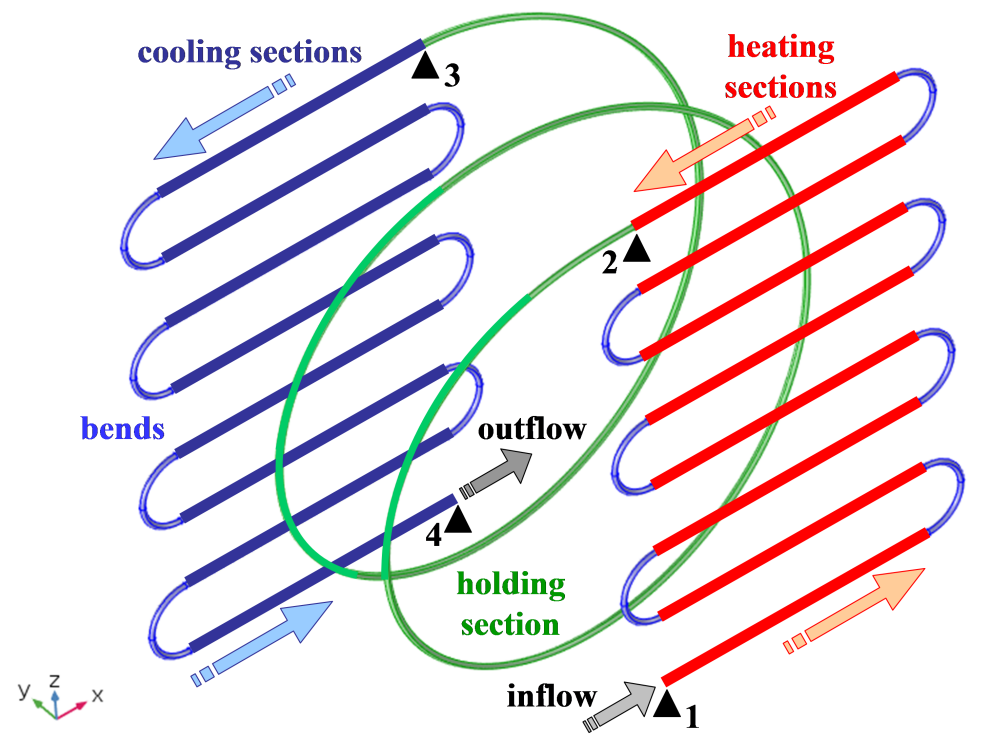

Figure 1: Tri-dimensional schematic representations of the heat exchanger under consideration. Heating sections are indicated in red, the holding section in green, cooling sections in dark blue, and bends in light blue; the heat exchanger's inlet and outlet are indicated. Positions 1 to 4 indicate where temperature measurements were conducted: at the inlet of the first heating section $\left(T_{\text {heater,inlet }}\right)$, at the outlet of the last heating section $\left(T_{\text {heater,outlet }}\right)$, at the inlet of the first cooling section $\left(T_{\text {cooler }, \text { inlet }}\right)$, and at the outlet of the last cooling section $\left(T_{\text {cooler,outlet }}\right)$, respectively.

ployed to identify the heat transfer coefficients required in the thermal boundary condition at the wall of heating and cooling sections (see 4.4). Finally, temperature and product transformation data obtained from experiments \#4 and \#5 were employed to assess the consistency of the numerical model 4.4 .

\subsection{Rheological parameters}

Figure 2 displays the available measurements of apparent viscosity of the liquid product. It became shear-thinning as the thermal denaturation-aggregation of whey proteins progressed; for a given shear rate, the apparent viscosity increased with the transformation state; for given shear rate and transformation state, the apparent viscosity decreased with the temperature.

The apparent viscosity of the liquid product is hereafter described through the following ap- proximations:

$$
\begin{gathered}
\eta\{\dot{\gamma}, \delta, T\}=K\{\delta, T\} \dot{\gamma}^{n\{\delta\}-1} \\
K\{\delta, T\}=a_{1} \exp \left(a_{2} /(R T)\right) \exp \left(a_{3} \delta\right) \\
n\{\delta\}=1-a_{4} \delta
\end{gathered}
$$

where $K$ is the consistency coefficient $\left(\mathrm{Pa} . \mathrm{s}^{n}\right)$, $n$ the flow behaviour index, and $\dot{\gamma}$ the shear rate $\left(\mathrm{s}^{-1}\right)$. Equations (10) express the mean dependence of the apparent viscosity with the shear rate, denaturation ratio and temperature, while requiring few parameters. Best fit values for the parameters required by equations (10) were estimated after minimizing the sum of squared deviations between the predictions and experimental values of the product apparent viscosity: $\mathrm{a}_{1}=3.6610^{-7} \mathrm{~s}^{n-1}, \mathrm{a}_{2}=2.5910^{4}$ J.mol ${ }^{-1}, \mathrm{a}_{3}=3.68$ and $\mathrm{a}_{4}=2.9910^{-1}$. Lines in Figure 2 indicate predictions of the apparent viscosity corresponding to the three thermal treatments; the averaged relative error between 
Table 1: Experimental results available to this study

\begin{tabular}{|c|c|c|c|c|c|}
\hline Experiment & $\# 1$ & $\# 2$ & $\# 3$ & $\# 4$ & $\# 5$ \\
\hline heat treatment & Weak & Medium & Strong & Strong & Strong \\
\hline holding temperature and holding time & $72^{\circ} \mathrm{C}, 20 \mathrm{~s}$ & $80{ }^{\circ} \mathrm{C}, 30 \mathrm{~s}$ & $94^{\circ} \mathrm{C}, 40 \mathrm{~s}$ & $94^{\circ} \mathrm{C}, 40 \mathrm{~s}$ & $94^{\circ} \mathrm{C}, 40 \mathrm{~s}$ \\
\hline condensation vapor temperature $\left({ }^{\circ} \mathrm{C}\right), T_{\text {vapor }}$ & 92.0 & 95.7 & 108.4 & 108.4 & 108.1 \\
\hline temperature at heater inlet $\left({ }^{\circ} \mathrm{C}\right), T_{\text {heater, inlet }}$ & 46.6 & 44.5 & 43.2 & 41.7 & 42.6 \\
\hline temperature at heater outlet ( $=$ at holder inlet) $\left({ }^{\circ} \mathrm{C}\right)$, & 71.8 & 79.8 & 93.8 & 93.8 & 93.8 \\
\hline temperature at cooler outlet $\left({ }^{\circ} \mathrm{C}\right), T_{\text {cooler,outlet }}$ & 42.6 & 43.0 & 39.6 & 44.2 & 45.3 \\
\hline initial conc. of native whey proteins $(\mathrm{kg} / \mathrm{m} 3), C_{\text {heater, } \text { inlet }}$ & 6.51 & 6.51 & 6.51 & 6.55 & 6.04 \\
\hline initial conc. of native whey proteins $(\mathrm{mol} / \mathrm{m} 3)$ & 0.355 & 0.355 & 0.355 & 0.357 & 0.330 \\
\hline initial conc. of native whey proteins (\%) & $16.6 \%$ & $16.6 \%$ & $16.6 \%$ & $16.7 \%$ & $15.4 \%$ \\
\hline denaturation ratio at cooler outlet & $6.0 \%$ & $17.0 \%$ & $62.0 \%$ & $64.9 \%$ & $61.0 \%$ \\
\hline
\end{tabular}

predictions and experimental values is about 9 $\%$.

The physical problem is two-way coupled. On one hand, the velocity field resulting from the solution of equations (1) and (2) drives heat and mass transfer, i.e. the temperature and concentration fields; in addition, the temperature field resulting from the solution of equation (3) drives the thermal denaturation-aggregation kinetics which is considered for estimating the concentration of native proteins (equations 4 and 5). On the other hand, both the temperature and the denaturation ratio of whey proteins affect the values assumed by the apparent viscosity of the liquid product (equations 10), which is a key variable in predicting the velocity field (equation 2).

The influence of thermal denaturationaggregation on the apparent viscosity is far more complex than the double role played by the denaturation ratio on equations (10). The concentration of native whey proteins decreases with the time, and the rate of such a decrease depends on the temperature (see Section 2); hence the local value of the denaturation ratio at a given position of the heat exchanger depends on the whole thermal and kinetics history experienced, since the inlet of the first heating section, by the fluid particles that are running at the position of the interest. A similar situation has been discussed in studying the coupled physical problem which involves fluid flow, heat transfer and swelling of starch granules in aqueous suspension inside a heat exchanger; the thermal history of fluid particles in the processing unit is implicitly taken into account when the physical problem is solved under stationary conditions (Plana-Fattori, Chantoiseau, Doursat, \& Flick, 2013).

\section{$4 \quad$ Numerical model}

The liquid product is hereafter characterized by the density $980 \mathrm{~kg} \cdot \mathrm{m}^{-3}$ (from measurements) and by the apparent viscosity approximated through equations (10). Because the large fraction of water in the liquid product $(60 \%$ in mass), both the specific heat capacity and the thermal conductivity are assumed to follow the behavior of pure water. The last line in Table 1 shows the Reynolds number at the heat exchanger inlet, i.e. where its highest value can be found for this liquid product and these operating conditions in the processing unit considered; the liquid product flows under laminar conditions. The computational strategy can be summarized as follows. In the numerical model, the processing unit is represented by a sequence of twodimensional, axi-symmetric computational domains. Displays A, B and C in Figure 3 illustrate such a representation for the first heating section. Figure 4 presents all the 31 domains that are required for representing the heating exchanger: eight heating sections separated by seven bends, one holding section, and eight cooling sections 


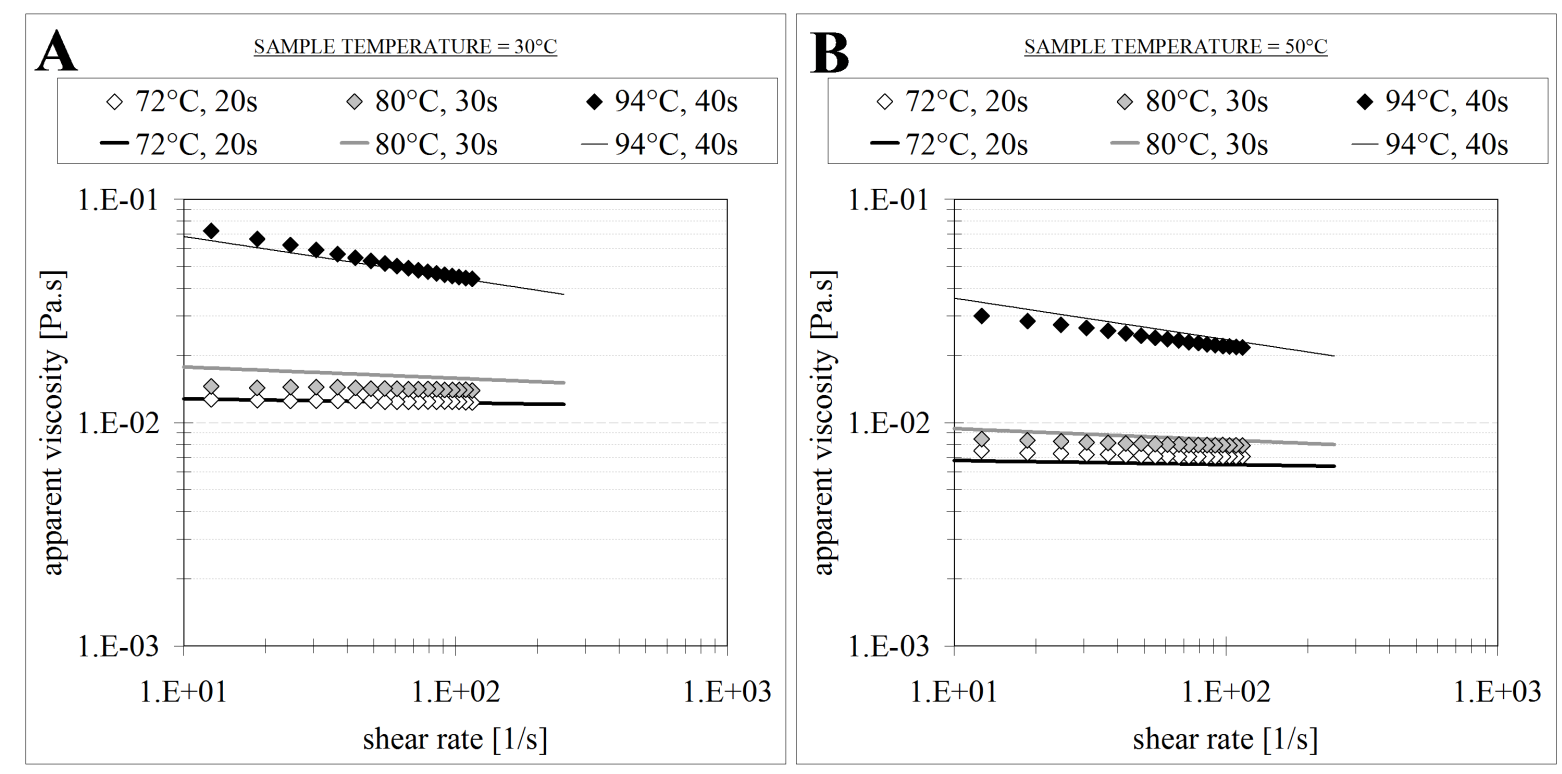

Figure 2: Apparent viscosity of the liquid product at $30{ }^{\circ} \mathrm{C}$ (display A) and $50{ }^{\circ} \mathrm{C}$ (display B), associated with the heat treatments conducted during experiments \#1, \#2 and \#3. Treatments are characterized by the holding temperature and the holding residence time. Triangles indicate measurements, and lines indicate predictions provided by equations (10) for the apparent viscosity as a function of the shear rate and denaturation ratio.

separated by seven bends. The coupled physical problem is solved successively for each domain, by assuming the boundary conditions described in 4.1. The mathematical methods employed for solving the problem are summarized in 4.2; the application of the finite-elements method requires the geometrical subdivision of computational domains, which is explained in 4.3. The final step of the model implementation involves the identification of heat transfer coefficients required by the thermal boundary conditions at the heating and cooling walls, as discussed in 4.4.

\subsection{Setting the boundary conditions}

A summary of the boundary conditions taken into account is provided in Table 2. Here they are described in further detail.

Inlet: Besides the first heating section, the radial profiles of velocity, temperature and concentration of native whey proteins profiles are assumed to follow model predictions at the outlet of the previous domain. At the inlet of the first heating section (i.e. the heat exchanger inlet), the flow is assumed to be fully-developed; moreover, the temperature and the concentration of native whey proteins follow the measured values $T_{\text {heater,inlet }}$ and $C_{\text {heater,inlet }}$, respectively (see Table 2 ).

Outlet: The product is assumed to flow normally to the boundary under no viscous stress; heat conduction and mass diffusion are both neglected.

Wall: The velocity field is assumed to vanish. Inward heat fluxes $h_{\text {heating }}\left(\mathrm{T}_{\text {vapor }}-\mathrm{T}\right)$ and $h_{\text {cooling }}\left(\mathrm{T}_{\text {water }}-\mathrm{T}\right)$ are applied in heating and cooling sections, respectively; $h_{\text {heating }}$ and $h_{\text {cooling }}$ are heating and the cooling transfer coefficients, $T_{\text {vapor }}$ is the condensation vapor temperature, and $T_{\text {water }}=5$ ${ }^{\circ} \mathrm{C}$. In the holding section, the product is

IJFS | January 2020 | Volume 9 | pages SI17-SI37 


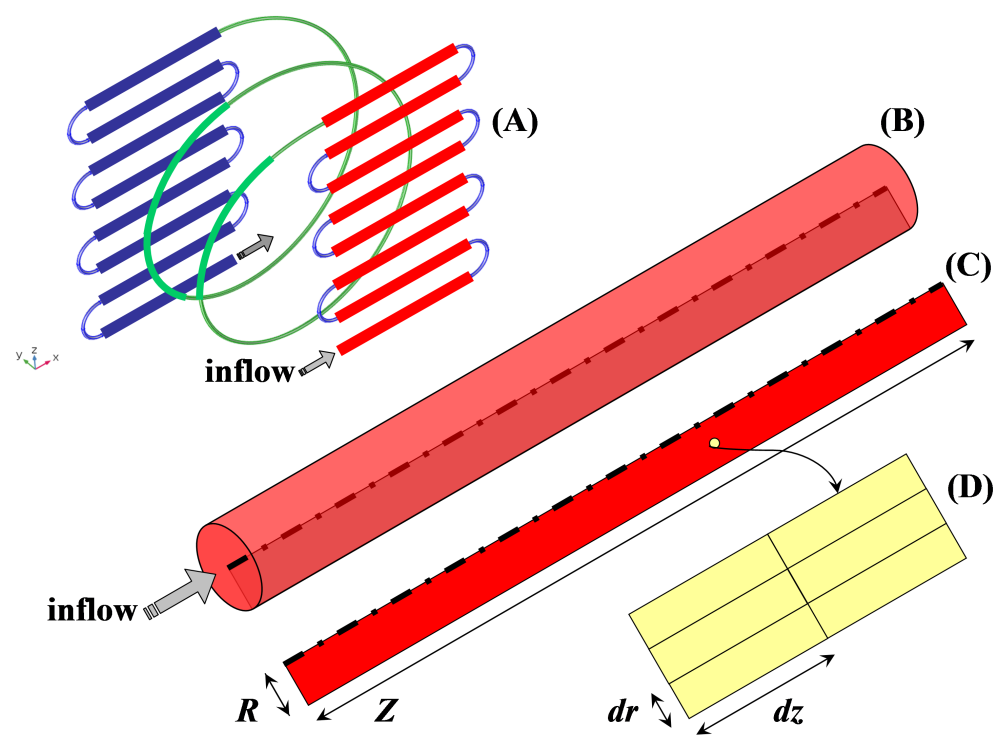

Figure 3: Schematic representation of the heat exchanger and of the strategy adopted for meshing the computational domains. Display A summarizes the heat exchanger shown in Figure 1. Display B is a close-up view of the first heating section; the slice is one axi-symmetric two-dimensional (2D) domain, and the dashed line is the axis of symmetry. Display $\mathrm{C}$ presents this $2 \mathrm{D}$ domain; its width $R=4 \mathrm{~mm}$ is the radius of all the tubular sections, while its length $Z$ depends on the section under consideration. Display D illustrates the mesh built around a given position in the first heating section. Features are not in scale.

exposed to uniform inward heat flux estimated from the section's global energy budget, by employing the measurements of temperature at its inlet $\left.T_{\text {heater, outlet }}\right)$ and its outlet $\left(T_{\text {cooler,inlet }}\right)$. The product is supposed to flow under thermally-insulated conditions in the bends.

Curved sections can play a mixing role, firstly in reducing the heterogeneity of temperature and composition, secondly in modifying the residence time distribution of fluid parcels (Ndoye, Erabit, Alvarez, \& Flick, 2012; Vashisth, Kumar, \& Nigam, 2008). The effectiveness of such a role depends on the geometrical features of the curved section, as well as on the relative importance of mechanisms due to molecular diffusion and to secondary flow (Kumar, Aggarwal, \& Nigam, 2006). We compared two extreme scenarios. In both scenarios, the thermal evolution of the liquid product inside the bends was predicted by the numerical model according to the boundary conditions specified above; in both scenarios, the radial distributions $u_{z}\{\mathrm{r}\}$, $\{\operatorname{Tr}\}$, and $C\{\mathrm{r}\}$ for axial velocity, temperature, and concentration of native proteins predicted at the bend outlet were employed to build the boundary conditions at the inlet of the following heating or cooling section.

no mixing: the model predictions of $u_{z}\{\mathrm{r}\}$, $T\{\mathrm{r}\}$, and $C\{\mathrm{r}\}$ at the bend outlet were applied, with no changes, as boundary conditions at the inlet of the following section; and

full mixing: firstly, the model predictions of $u_{z}\{\mathrm{r}\}, T\{\mathrm{r}\}$, and $C\{\mathrm{r}\}$ at the bend outlet were employed for computing the massweighted (bulk) values $\tilde{T}$ and $\tilde{C}$ for temperature and concentrative of native proteins; secondly, these bulk values were applied as 


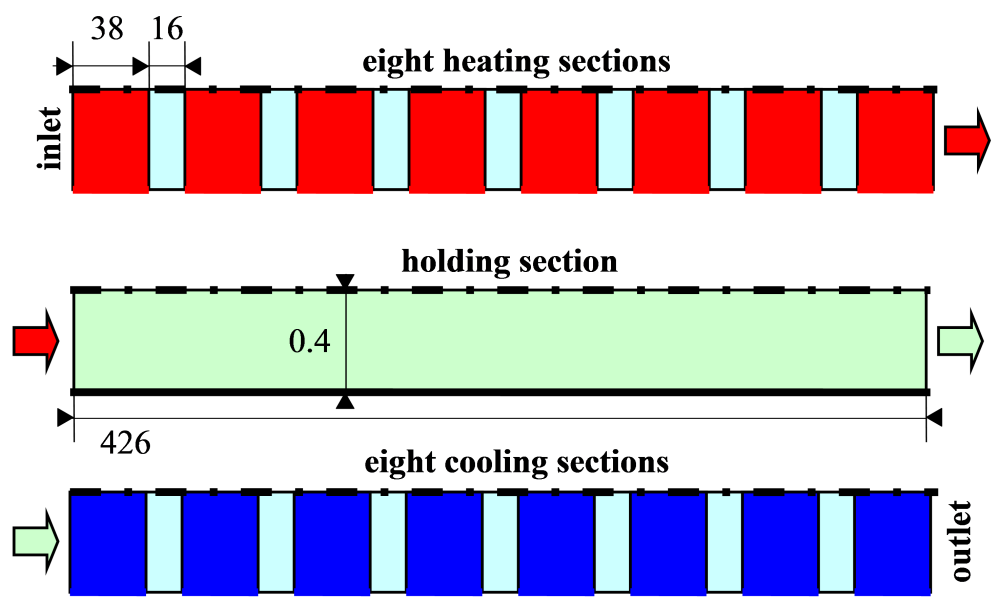

Figure 4: Two-dimensional axi-symmetrical schematic representations of the heat exchanger under consideration. Heating sections are indicated in red, the holding section in green, cooling sections in dark blue, and bends in light blue; the heat exchanger's inlet and outlet are indicated. Dashed lines indicate the axis of symmetry, and red and dark blue lines indicate heating and cooling walls; heating and cooling sections are geometrically identical; and all the dimensions are indicated in centimeters (features not in scale).

boundary conditions at the inlet of the following section; finally, the axial velocity at the inlet of following section was expressed as (Brodkey, Lee, \& Chase, 1961):

$$
u_{z}\{r\}=\bar{u}_{z}\left(\frac{3 \tilde{n}+1}{\tilde{n}+1}\right)\left(1-\left(\frac{r}{R}\right)^{\tilde{n}+1 / \tilde{n}}\right)
$$

where $\tilde{n}$ is the flow behavior index given through equation (10) after replacing $\delta$ by $\tilde{\delta}_{\text {bend,outlet }}$, where $\tilde{\delta}_{\text {bend,outlet }}=1-\tilde{C}_{\text {bend,outlet }} / \mathrm{C}_{\text {heater, intlet }}$.

\subsection{Solving the problem}

The finite-element method was employed for solving the coupled physical problem constituted by the governing equations $(1,2,3$, and 5), applied to the liquid product of interest and to the computational domains displayed in Figure 3 , while respecting the boundary conditions summarized in Table 2. The finite-element method for solving problems in engineering and mathematical physics had been developed decades ago - To solve the problem, this method subdivides the whole domain of interest into smaller, simpler parts that are called finite elements. In the finiteelement method, instead of solving the problem for the entire body in one operation, the equations are formulated for each finite element and combine them to obtain the solution of the whole body (Pepper, Kassab, \& Divo, 2014).

The finite-element method was employed as implemented in the simulation package COMSOL Multiphysics software (version 5.2.0.220; COMSOL, Inc., Burlington, Massachusetts) (Zimmerman, 2006). Phenomena of fluid flow, heat transfer and thermal denaturation-aggregation were represented with the help of three COMSOL Multiphysics interfaces: "Laminar Flow" (for equations 1 and 2), "Heat Transfer in Fluids" (equation 3), and "Transport of Diluted Species" (equation 5). In addition, the COMSOL Mul- 
Table 2: Summary of boundary conditions assumed for the radial $u_{r}$ and axial $u_{z}$ components of the velocity, for the temperature $T$ and for the concentration of native proteins $C$.

\begin{tabular}{llll}
\hline & fluid flow & heat transfer & transformation \\
\hline Inlet $(+)$ & velocity: $u_{r}=0, u_{z}\{r\}$ & temperature: $T\{r\}$ & concentration: $C\{r\}$ \\
Outlet & null pressure, no viscous stress & convective flux: $\partial T / \partial z=0$ & convective flux: $\partial C / \partial z=0$ \\
Axis & symmetry: $u_{r}=0,\left(\partial u_{z}\right) / \partial r=0$ & symmetry: $\partial T / \partial r=0$ & symmetry: $\partial C / \partial r=0$ \\
Wall & no slipping: $u_{r}=u_{z}=0$ & inward heat flux & no diffusion: $\partial C / \partial r=0$ \\
\hline
\end{tabular}

(+) Excepting the inlet of the first heating section, where the temperature and the concentration of native proteins follow the measured values

$T_{\text {heater,inlet }}$ and $C_{\text {heater,inlet }}$, and the axial velocity follows the fully-developed parabolic profile associated with the volume flow rate (see Table 1).

tiphysics "LiveLink for MATLAB" was used to drive the resolution of the problem over the sequence of computational domains.

Discretization of equations (1, 2, 3, and 5) considered second-order Lagrange finite elements for the velocity components, the temperature and the concentration of native proteins, and first-order elements for the pressure. The linear system obtained after discretization and linearization of governing equations was solved by applying the Multifrontal Massively Parallel Sparse Direct Solver (MUMPS) (Amestoy, Duff, L'Excellent, \& Koster, 2001) with a relative tolerance smaller than $10^{-5}$.

\subsection{Meshing the domains}

The resolution of governing equations through the finite-element method requires the subdivision of the computational domain into a number of small, non-overlapping cells (the mesh elements). The geometry of the domains suggested the adoption of a structured mesh, constituted of rectangular cells, characterized by dimensions $d r$ and $d z$ in the radial $(r)$ and in the axial direction $(Z)$, respectively. Indicating by $R$ the domain's width and $Z$ its length, the total number of mesh cells in a given domain can be written as $n r \times n z$, where $n r=\frac{R}{d r}$ and $n z=\frac{Z}{d z}$ are the numbers of cells in the radial and in the axial direction, respectively. We choose cells whose length is four times their width $\frac{d z}{d r}=4$, as a compromise for representing gradients along both directions. Display D in Figure 3 illustrates these concepts, around a given position in the first heating sec- tion.

A mesh with relatively high resolution was adopted, corresponding to $n r=2^{7}=128$. This is the finest resolution allowed by our computer resources (192-Gb RAM) for solving the coupled problem in the holding section $(Z=4.26 \mathrm{~m})$. Adopting such a resolution, about 13 million cells were required for meshing all the $31 \mathrm{com}-$ putational domains which represent the heat exchanger. The influence of the mesh resolution is discussed in Subsection 5.2.

\subsection{Identifying the heat transfer coefficients}

The last step in implementing the numerical model was the identification of heat transfer coefficients $h_{\text {heating }}$ and $h_{\text {cooling }}$, which are required in the specification of the thermal boundary conditions at the walls of the heating and cooling sections (see Table 2). Such a task was performed by comparing measured temperatures from experiments \#1, \#2 and \#3 and corresponding model predictions. Firstly, $h_{\text {heating }}$ was identified by minimizing the departure between the bulk value of temperature predicted at the outlet of the last heating section and the corresponding experimental value $T_{\text {heater, outlet }}$ ); secondly, $h_{\text {cooling }}$ was identified by minimizing the departure between the bulk value of temperature predicted at the outlet of the last cooling section and the corresponding experimental value ( $\left.T_{\text {cooler, outlet }}\right)$.

The representation of coupled phenomena under the scenarios "no mixing" and "full mixing" in 
the bends required different values for the heat transfer coefficient values at heating and cooling walls:

full mixing: $h_{\text {heating }}=1025 \mathrm{~W} \cdot \mathrm{m}^{-2} \cdot \mathrm{K}^{-1}$ and $h_{\text {cooling }}=475 \mathrm{~W} \cdot \mathrm{m}^{-2} \cdot \mathrm{K}^{-1} ;$ and

no mixing: $h_{\text {heating }}=9000 \mathrm{~W} \cdot \mathrm{m}^{-2} \cdot \mathrm{K}^{-1}$ and $h_{\text {cooling }}=1030 \mathrm{~W} \cdot \mathrm{m}^{-2} \cdot \mathrm{K}^{-1}$.

The denaturation ratio of whey proteins at the heat exchanger outlet was $6.0 \%, 17.0 \%$ and $62.0 \%$ respectively for experiments $\# 1, \# 2$ and \#3 (see Table 1). These observations can be compared with the corresponding mass-weighted values $\quad \tilde{\delta}_{\text {cooler,outlet }}=1-\frac{\tilde{C}_{\text {cooler, outlet }}}{C_{\text {heater, } \text { inlet }}}$ that were predicted at the heat exchanger outlet after applying the numerical model to the operating conditions of these three experiments. Indeed, after assuming "full mixing" at the bends" outlet, model predictions provided $\tilde{\delta}$ of about $0.4 \%, 3.4 \%$ and $55.4 \%$, say $-5.6 \%,-13.6 \%$ and $-6.6 \%$ with respect to the experimental value; after assuming "no mixing" at the bends' outlet, model predictions provided $\tilde{\delta}$ of about $3.0 \%$ $(-3.0 \%), 9.8 \%(-7.2 \%)$ and $51.4 \%(-10.6 \%)$, respectively for experiments \#1, \#2 and \#3. Two results emerge from these tests.

- On one hand, the numerical model consistently underestimates the denaturation ratio of whey proteins as observed at the heat exchanger outlet. In assuming that the thermal denaturation- aggregation behavior exhibited by all the whey proteins in the liquid product is described through the approach proposed by Tolkach and Kulozik (2007) for beta-lacto-globulin in suspension, we have neglected the influence of other whey proteins on the overall denaturation ratio of the product, as well as the influence of other constituents of the product.

- On the other hand, the influence of the bends' mixing effectiveness on model predictions seems to be secondary in the case study here considered. Hereafter, in applying the numerical model to the study of the liquid product under thermal processing, only the scenario "full mixing" at the bends' outlet was considered.
These comparisons considered observations and model predictions corresponding to the operating conditions of experiments \#1, \#2 and \#3; their datasets contributed to the implementation of the numerical model, either in the estimation of rheological parameters (see equations 10) or in the identification of heat transfer coefficients.

Two final simulations were carried out to assess the reliability of the numerical model, by considering observations which did not contribute to its implementation. The denaturation ratio of whey proteins at the heat exchanger outlet was $64.9 \%$ and $61.0 \%$ respectively for experiments \#4 and \#5 (see Table 1); after assuming "full mixing" at the bends' outlet, model predictions provided $\tilde{\delta}$ of about $54.7 \%(-10.2 \%)$ and $50.7 \%$ ($10.3 \%)$, respectively. In other words, in the case of the strongest heat treatment, a similar level of agreement between model predictions and observations is reached either for the experiment that contributed to the implementation of the numerical model $(\# 3)$ or for those that did not (\#4 and \#5).

\section{$5 \quad$ Results}

\subsection{Coupled phenomena throughout the heat exchanger}

One major advantage of physics-based numerical modelling is the assessment of distributions of velocity, temperature and other variables at scales beyond current experimental capabilities. Figures 5-11 display model predictions obtained under the operating conditions of experiment \#3, say the strongest heat treatment here considered (holding temperature $94{ }^{\circ} \mathrm{C}$, holding time $40 \mathrm{~s}$ ); the coupling between phenomena of fluid flow, heat transfer and thermal denaturationaggregation are expected to be the most significant.

Figure 5 shows the temperature. In the heating sections, the temperature increases more slowly at the axis of symmetry because the liquid product is warmed from the wall; in the cooling sections, the temperature decreases more slowly at the axis of symmetry because the liquid product is cooled from the wall. In the 
holding section, whose walls are assumed to be thermally-insulated and whose outlet and inlet are at about the same temperature (Table 1), the radial variations of temperature progressively vanish. In the bends, the product flows under thermally-insulated conditions; in bends situated after a heating section (cooling section), convective transfer promotes heating (cooling) from the vicinity of the wall towards the axis of symmetry. Figure 6 shows the denaturation ratio. The highest value occurs at the wall at the holding section outlet, due to the longer residence times at the wall. At the scale of the whole heat exchanger, the scenario "full mixing" accelerates the thermal denaturation-aggregation at the axis of symmetry while slowing it down near the heating walls. Product transformation is virtually halted after the second cooling section.

Figure 7 presents the flow behavior index $n$ At the heat exchanger inlet, the liquid product was assumed to exhibit a Newtonian behavior due to the occurrence of native proteins only $(\delta=0)$ Along the liquid product pathway, the behavior index was assumed to decrease linearly with the denaturation ratio (equation 10); hence they exhibit similar axial and radial variations, being that the lowest value of $\delta$ occurs at the wall of the holding section outlet.

Figure 8 shows the consistency coefficient $K$; it was assumed to increase exponentially with the denaturation ratio while decreasing with the temperature (equation 10). The influence of the thermal denaturation-aggregation of whey proteins is dominant, excepting: near the walls of the first heating sections (under weak thermal denaturation-aggregation) and also near the walls of the last cooling sections (under almost constant denaturation ratio).

Figure 9 exhibits the apparent viscosity $\eta$; it was assumed to follow a power-law representation, with local values depending on temperature, shear rate, and denaturation ratio. Its spatial distribution is complex even under nearly isothermal conditions, as those prevailing near the holding section outlet: on one hand it increases near the axis of symmetry, under vanishing shear rate values (Figure 11); on the other hand, it increases in the vicinity of the wall too, under relatively high denaturation ratio values (see Figure 6).
Model predictions of velocity magnitude and shear rate are presented in Figures 10 and 11, respectively. At the heat exchanger inlet, the flow was assumed to be fully-developed; at the inlet of a section succeeding a bend, the velocity field was assumed to follow the developed profile whose flow behaviour index corresponds to the bulk value of the denaturation ratio at the bend outlet (see equation 11). Along the first heating sections, the velocity magnitude decreases at the axis, whereas it increases in the vicinity of the wall; such a result can be related to the apparent viscosity values at the wall, which decreases as a consequence of progressive warming under low product transformation. On the contrary, along the remaining heating sections, the velocity magnitude increases at the axis and decreases near the wall as a consequence of product transformation and increase in apparent viscosity near the wall: fluid parcels travelling in the vicinity of the wall are slowed down, while those running at the axis undergo acceleration. As shown in Figure 11, this second pattern allows progressively high shear rate values along a tongue-like region which separates the vicinity of the heating wall and the region near the axis. Such a tongue-like region can also be recognized in the cooling sections, where the highest values of apparent viscosity occur in the vicinity of the cooling wall and also near the axis of symmetry.

\subsection{Influence of mesh resolution}

The above results were obtained after adopting $n r=2^{7}=128$ rectangular cells in the radial direction when subdividing all the computational domains (see 4.2). The influence of mesh resolution was assessed by coarsening that subdivision, firstly by adopting $n r=2^{6}=64$ and later $n r=2^{5}=32$ cells. Model convergence for these two meshes required the diffusion coefficients $d_{S}=2 \cdot 10^{-8}$ and later $d_{S}=10^{-7} \mathrm{~m}^{2} . \mathrm{s}^{-1}$ in equation (5), respectively. Results were obtained after assuming "full mixing" at the bends' outlet.

Figure 12 compares model predictions of the denaturation ratio at the outlet of the last heating section, where the radial variations in temperature and degree of denaturation are the highest 

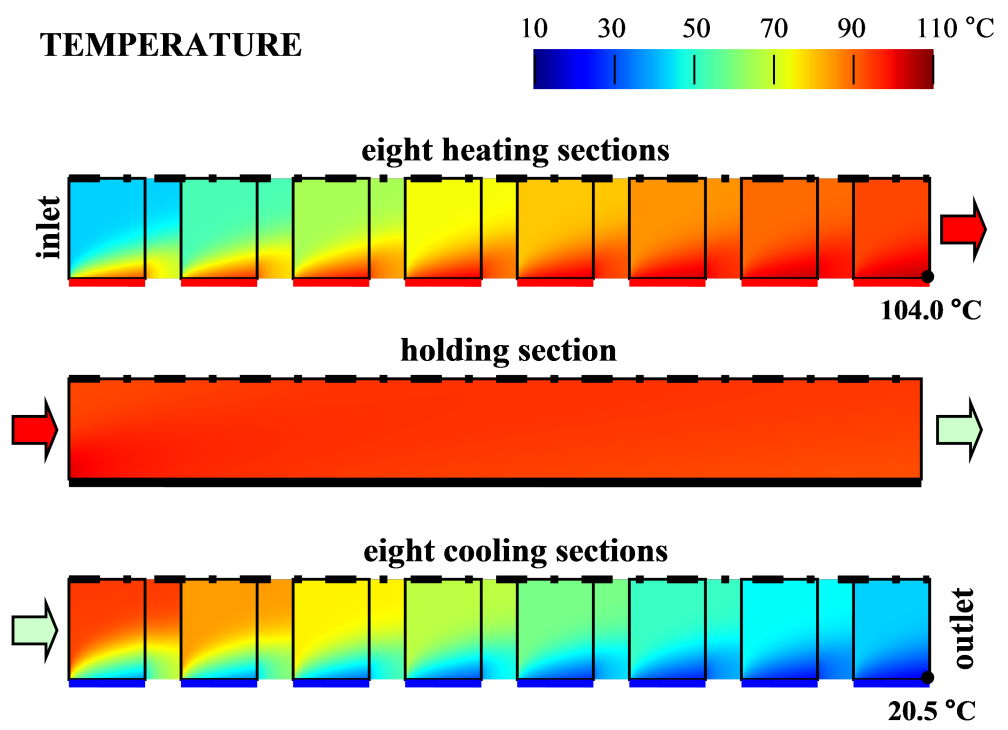

Figure 5: Numerical model predictions for the liquid temperature throughout the heat exchanger, considering the operating conditions of experiment \#3, assuming "full mixing" at the bends' outlet. The lowest and the highest values are also indicated.

(see Figures 5 and 6); model predictions correspond to the operating conditions of experiment \#3 (holding temperature $94{ }^{\circ} \mathrm{C}$, holding time 40 $\mathrm{s})$. Display A shows results obtained after adopting $n r=128$, while display $\mathrm{B}$ presents the differences between results from a given mesh and those shown in display A. Differences are negative (i.e. thermal denaturation-aggregation is underestimated) in the vicinity of the heating wall; they become stronger with the coarsening of the mesh, and this can be explained by the progressively-poorer representation of the gradients of state variables. Further, differences are slightly positive across a wide region near the axis of symmetry, due to additional diffusion of transformed product from the heating wall. Taking as reference the denaturation ratio value of about $50 \%$ predicted by the model at the wall after adopting $n r=128$, the impact of adopting firstly $n r=64$ and later 32 can reach $-5.4 \%$ and later $-14.9 \%$, respectively.

The overall influence of the mesh resolution can be assessed in terms of the mass-weighted value of the concentration of remaining native proteins in the liquid product at the heat exchanger outlet, $\tilde{C}_{\text {cooler,outlet }}$ or its interpretation $\tilde{\delta}_{\text {cooler,outlet }}$ $=1-\tilde{C}_{\text {cooler,outlet }} / \mathrm{C}_{\text {cooler }, \text { outlet }}$ in denaturation ratio units. After assuming 32, then 64, and finally 128 rectangles in the radial direction, model predictions of $\tilde{\delta}_{\text {cooler,outlet }}$ were respectively $59.4 \%, 56.7 \%$ and $55.4 \%$ in the case of experiment \#3. Differences between results associated with two successive meshes decrease as the latter become finer, suggesting a convergence-like behavior. We argue that a further leap in mesh resolution (from $n r=2^{7}=128$ to $=2^{8}=256$ ) would allow closer results, i.e. the differences between successive predictions of the outlet bulk denaturation ratio would be smaller than $1 \%$ in denaturation ratio units.

\subsection{The numerical model as a tool for experiments}

One advantage of physics-based models is their predictive capability, which enables the analysis of "what if" scenarios (Datta, 2008).

In the numerical model, the holder element of 


\section{DENATURATION RATIO

eight heating sections

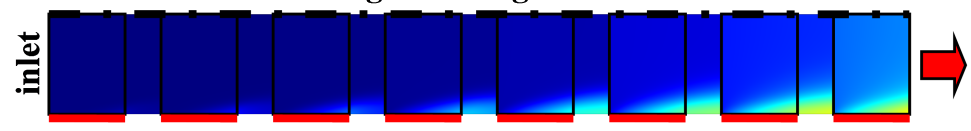

holding section

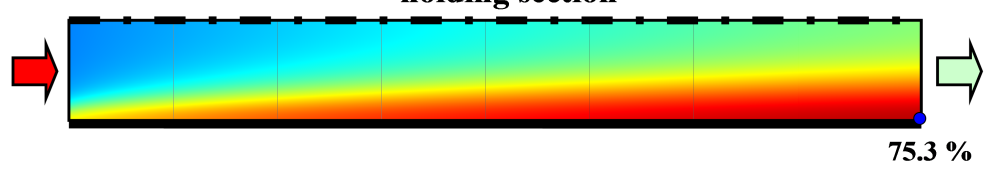

eight cooling sections

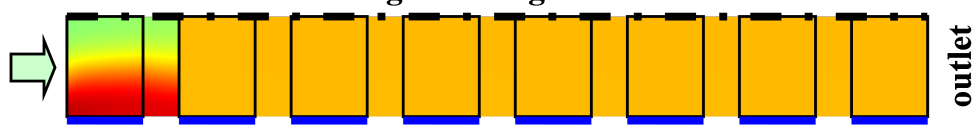

Figure 6: As in Fig. 5 but for the denaturation ratio. The highest value is also indicated; vanishing values occur along the heat exchanger inlet.
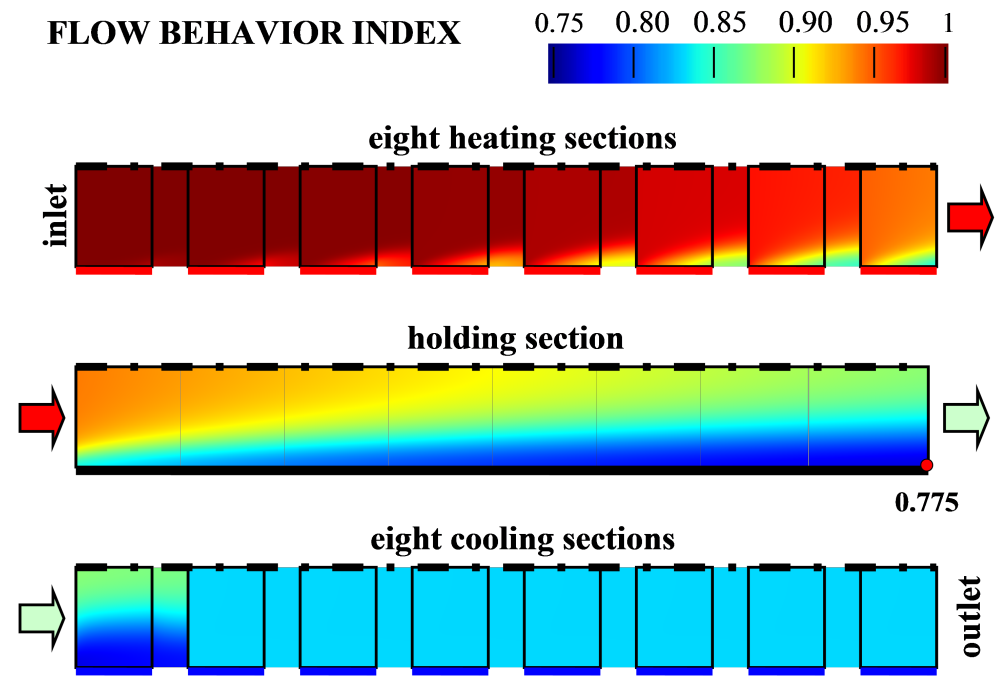

Figure 7: As in Fig. 5 but for the flow behavior index. The lowest value is also indicated; the behavior index equals the unity along the heat exchanger inlet. 


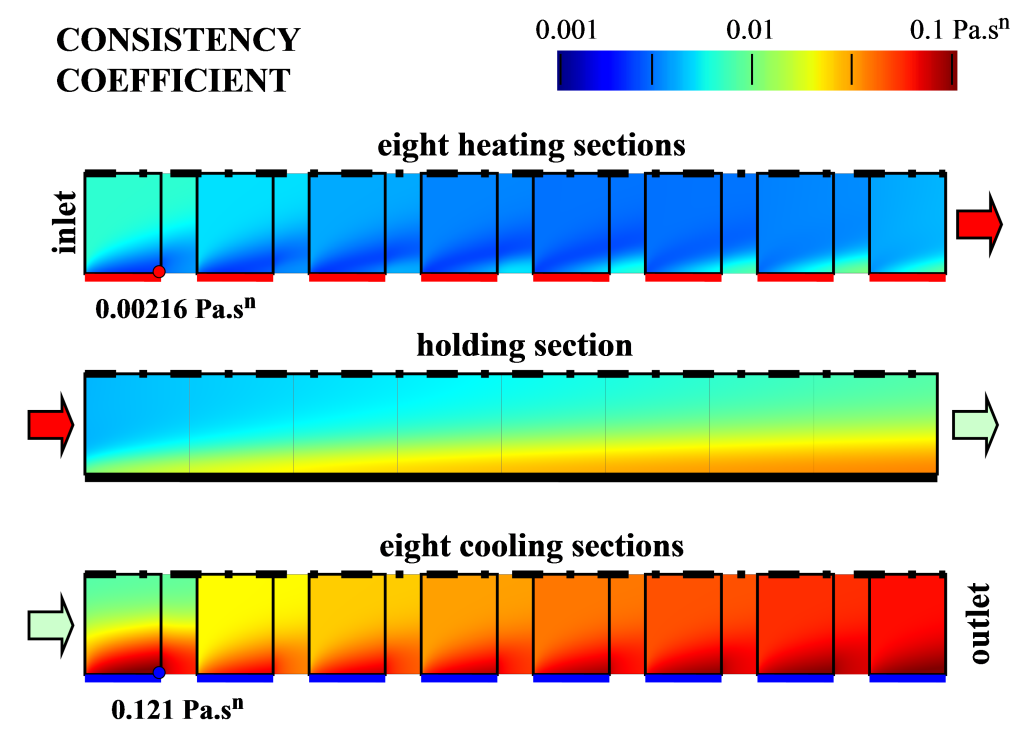

Figure 8: As in Fig. 5 but for the consistency coefficient

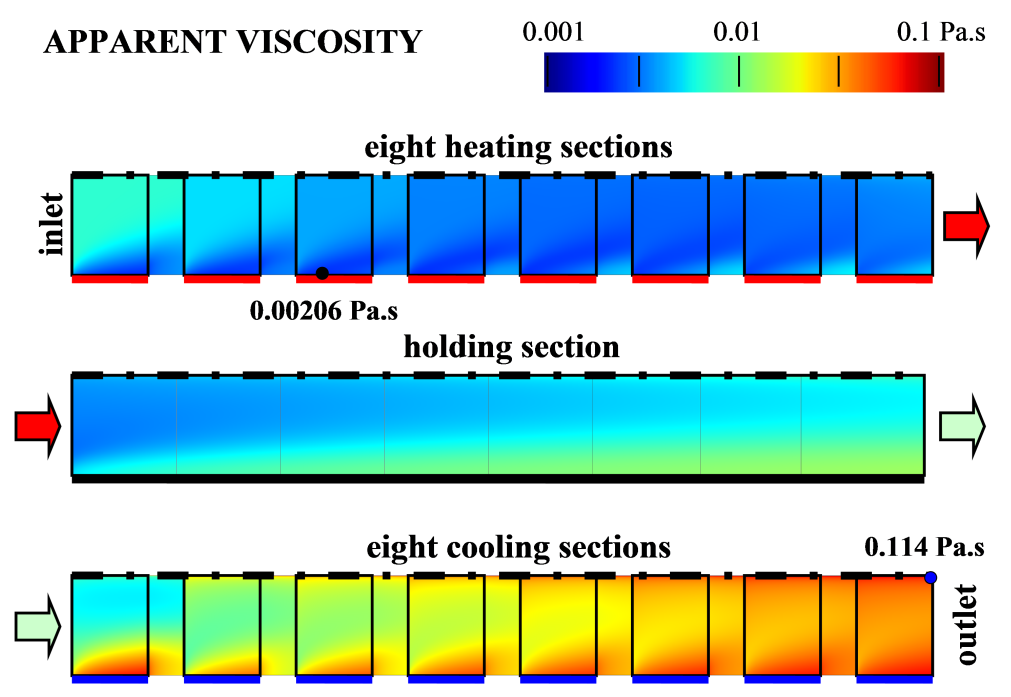

Figure 9: As in Fig. 5 but for the apparent viscosity 

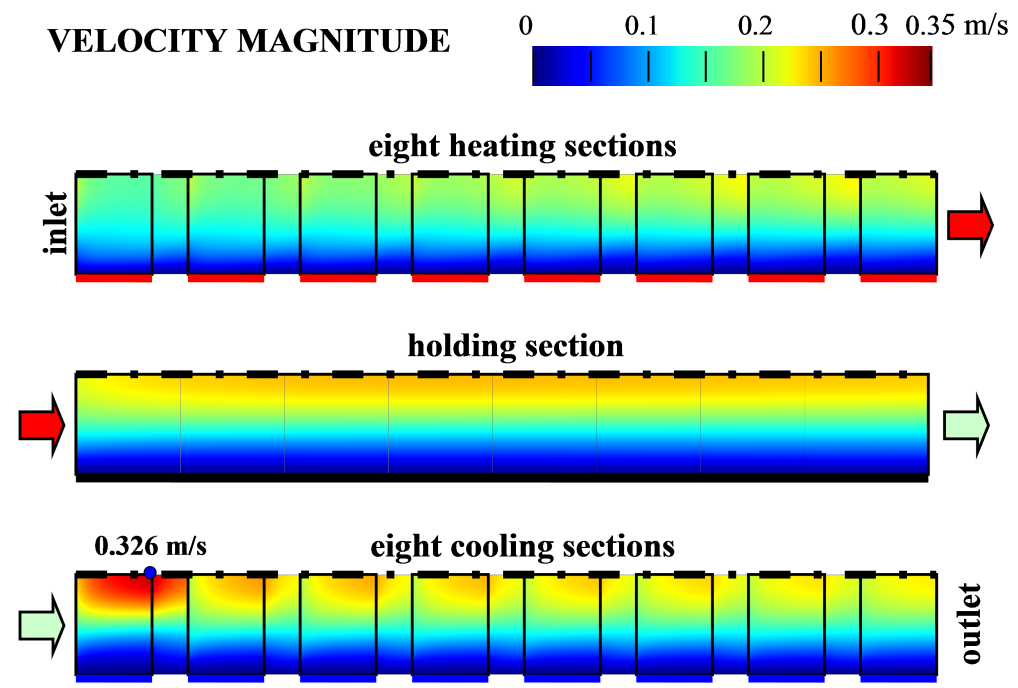

Figure 10: As in Fig. 5 but for the velocity magnitude. The highest value is also indicated; vanishing values occur along the walls
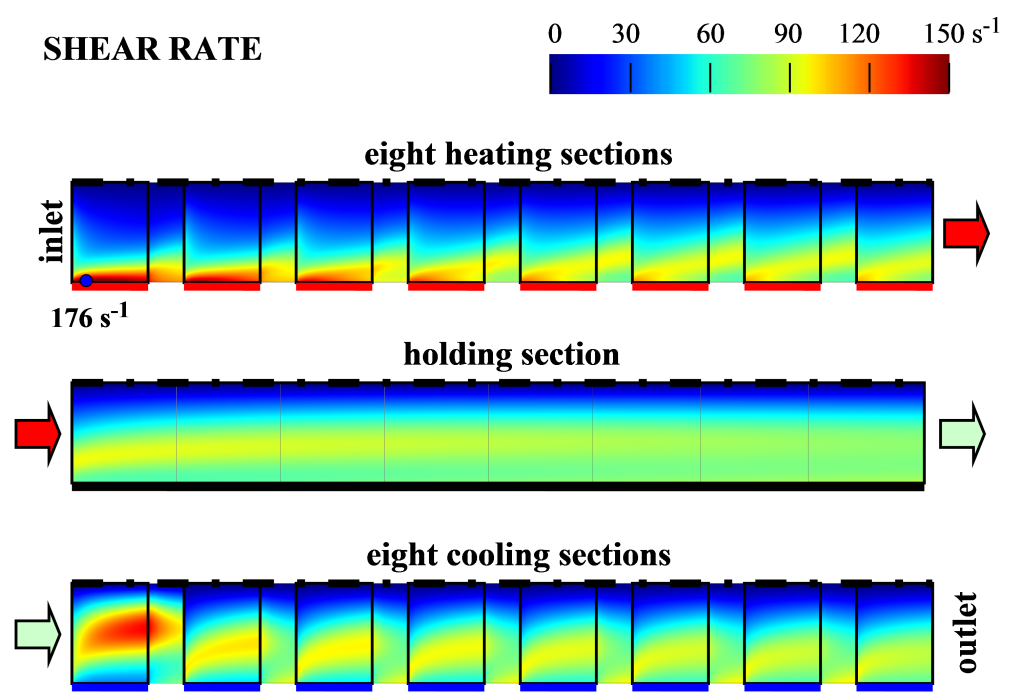

Figure 11: As in Fig. 5 but for the shear rate. The highest value is also indicated; vanishing values occur along the axis of symmetry. 


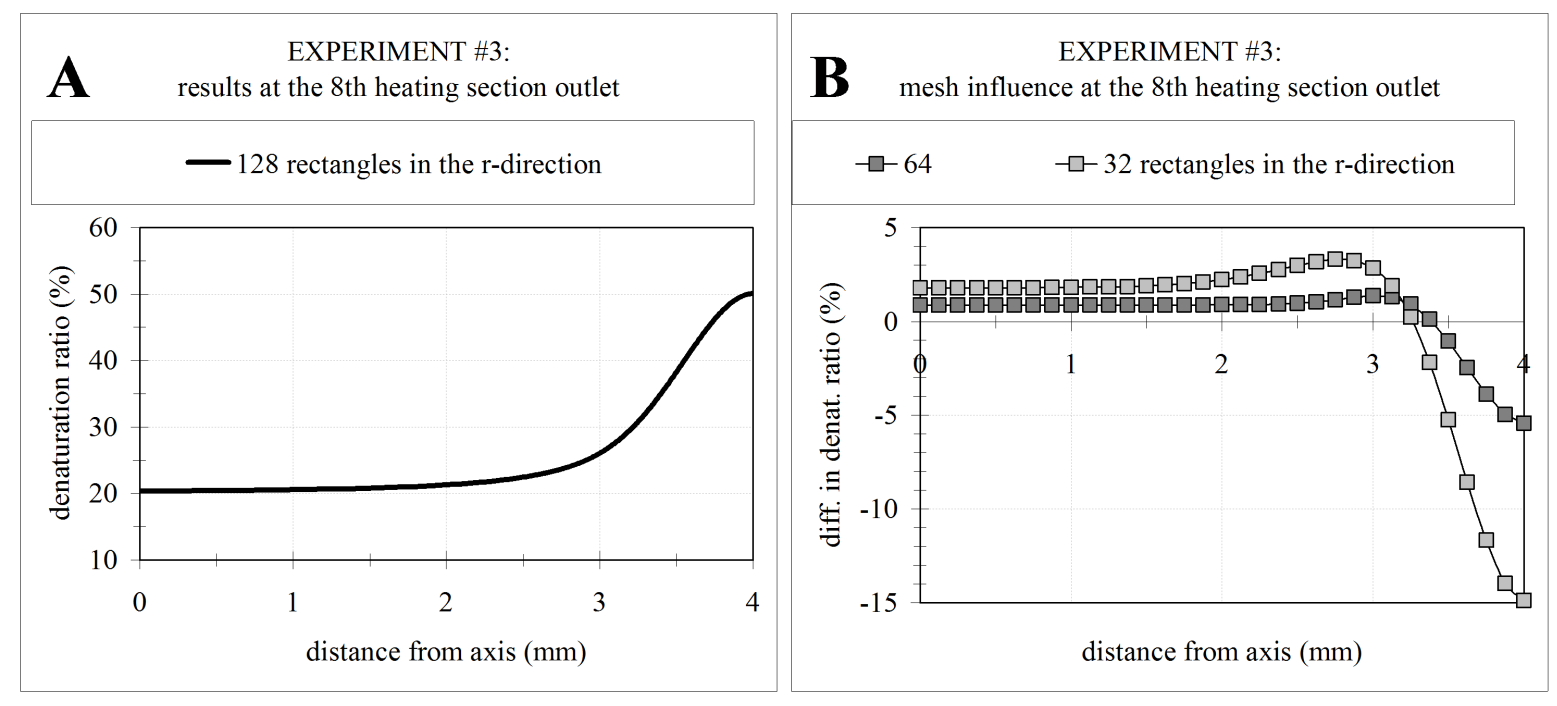

Figure 12: Denaturation ratio of the liquid product after the strongest heat treatment of the experiment \#3 as predicted by the numerical model at the outlet of the last heating section: A) results obtained after assuming a mesh consisting of 128 identical rectangles in the radial direction; B) difference between results obtained after adopting successively 64 and 32 rectangles in the radial direction, and results shown in display A.

the pilot scale unit is represented as a cylindrical tube with length $L_{\text {hold }}=4.26 \mathrm{~m}$. Model predictions provided the values $\tilde{\delta}_{\text {heater, outlet }}=23.7 \%$ at the outlet of the last heating section, $\tilde{\delta}_{\text {holder, outlet }}$ $=54.3 \%$ at the outlet of the holding section, and $\tilde{\delta}_{\text {cooler }, \text { outlet }}=55.4 \%$ at the heat exchanger outlet. The bulk contributions due to the heating, holding and cooling sections are hence $23.7 \%$, $54.3 \%-23.7 \%=30.6 \%$, and $55.4 \%-54.3 \%=$ $1.1 \%$ in denaturation ratio units. As suggested in Figure 6, the contribution due to the cooling sections is nearly negligible.

Two simple exercises were conducted to assess the impact of changes in the length of the holding section on model predictions. Operating conditions of experiment \#3 (holding temperature $94{ }^{\circ} \mathrm{C}$, holding time $40 \mathrm{~s}$ ) and the scenario "full mixing" at the bends's outlet were taken into account. No changes, other than the length of the holding section, were operated in the numerical model.

After reducing the length of the holding section to $50 \%$ of its reference value, model predictions provided the values $\tilde{\delta}_{\text {holder, outlet }}=43.2 \%$ and $\tilde{\delta}_{\text {cooler }, \text { outlet }}=43.8 \%$; the contribution due to the holding and cooling sections decreased to $43.2 \%$ $23.7 \%=19.5 \%$ and $43.8 \%-43.2 \%=0.6 \%$ in denaturation ratio units. Inversely, after increasing the length of the holding section to $150 \%$ of its reference value, model predictions provided the values $\tilde{\delta}_{\text {holder,outlet }}=62.8 \%$ and $\tilde{\delta}_{\text {cooler,outlet }}=$ $63.6 \%$; the contribution due to the holding and cooling sections increased to $62.8 \%-23.7 \%=$ $39.1 \%$ and $63.6 \%-62.8 \%=0.8 \%$ in denaturation ratio units.

The denaturation ratio $\tilde{\delta}_{\text {holder,outlet }}$ increases with the length of the holding section because the latter drives the residence times of fluid parcels at temperatures associated with significant thermal denaturation-aggregation (see Figures 5 and $6)$. The consequences of changing the length of the holding section are quite small on the impact due to the cooling sections on the final value $\tilde{\delta}_{\text {cooler,outlet }}$ at the heat exchanger outlet.

The numerical model was implemented for solving a direct problem: assuming a given combination of geometry and boundary conditions, the model predicts the final state of the liquid prod- 
uct of interest at the heat exchanger outlet. The exercises above demonstrate that the same numerical model can be employed as a tool for identifying possible solutions for the corresponding inverse problem; for instance, process designers might look for selected geometry configurations allowing the prescribed final state of the liquid product.

\section{Summary and future work}

This study represents the logical continuation of previous efforts (Chantoiseau, Plana-Fattori, Doursat, \& Flick, 2012) in modelling the thermal processing of a liquid product containing whey proteins. In that contribution, the coupled physical model neglected the influence of the regime transition near $90{ }^{\circ} \mathrm{C}$ for the temperature dependence of the thermal denaturation-aggregation kinetics rate, as well as the progressively shearthinning rheological behavior of the liquid product along its transformation history; both issues were effectively taken into account here. Further, the development of a liquid product of industrial interest (the cream cheese formulation of Coutouly et al. (2014)) was here discussed inside the tubular sections that represent the processing pilot unit. Experimental data from those authors allowed us to identify the external heat transfer coefficients required in the thermal boundary conditions to be applied at the walls of heating and cooling sections as represented in the 2D axi-symmetric numerical model. About the latter issue, the identification of heat transfer coefficients represented a key step in closing the problem: $h_{\text {heating }}$ and $h_{\text {cooling }}$ were estimated by comparing model predictions and observations, and therefore their values implicitly include the impact of approximations performed in implementing the numerical model. For instance, because its relatively high mass fraction in the liquid product $(60 \%)$, pure water was considered a first candidate for describing the thermal properties required for solving the coupled physical problem.

In the case of the strongest heat treatment, the difference between model predictions and measurements of denaturation ratio of whey proteins at the heat exchanger outlet ranged from
$-10 \%$ to $-11 \%$ in denaturation ratio units. This systematic behaviour occurs for experiment \#3, which helped us to implement the model through the identification of rheological parameters and heat transfer coefficients, as well as for experiments \#4 and \#5, which did not contribute to the model implementation. Such a bias may be associated with the key assumption considered in implementing the numerical model: the strict validity of the Tolkach and Kulozik (2007)'s approach for describing the thermal denaturation-aggregation behavior of the whey proteins present in the cream cheese formulation of Coutouly et al. (2014). This assumption implies that the occurrence of other whey proteins in the liquid product (like lacto-albumins) were ignored, as well as the influence of other constituents which are present in the liquid product (like fat and caseins). A first conclusion of this study is that the Tolkach and Kulozik (2007)'s approach can be included in a numerical model for solving the coupled physical problem under consideration, allowing consistent results. The next logical steps about this issue should be: a) the test of this numerical model with experimental data from the thermal continuous processing of simpler liquid products (for instance, no other whey protein than beta-lacto-globulin), and b) the analysis of model predictions obtained after replacing that approach by a similar formalism able to consider more complex constitution of the liquid product.

Relatively powerful computational resources were required to obtain numerical solutions of the coupled physical problem; each run required about 12 hours duration of exclusive use of one 192-Gb RAM computer. The adoption of a highresolution mesh (128 rectangles in the radial direction, over a distance of $4 \mathrm{~mm}$ ) allowed a fine description of the variations experienced by key variables. To the author's knowledge, no previous study has displayed the 2D axi-symmetrical distributions of the apparent viscosity for a nonNewtonian liquid product, identifying the axial and radial variations of the consistency coefficient and the flow behavior index along the tubular sections which constitute a thermal processing unit. For instance, along the holding section, the denaturation ratio decreases from the wall, and the shear-thinning behaviour become less 
pronounced towards the axis of symmetry. An important result from this study is that, superimposed to the progressive thermal denaturationaggregation of the whey proteins in the liquid product since the heat exchanger inlet, radial dependence was predicted for all the variables under consideration, including transport properties. Such dependence might be anticipated in building the coupled physical problem (Section 2); model predictions revealed, further, how much this dependence can evolve along a given tubular section, and how much it can vary from a tubular section to another.

The final concluding remark concerns the flexibility of the numerical model here implemented. The problem is solved successively for the sequence of computational domains, while translating model predictions at a given outlet into boundary conditions at the following inlet. It is relatively easy to insert or to remove tubular sections before producing new predictions, demonstrating the potential of the numerical model as a design tool. Attention should be paid to the comparison of selected future scenarios with experimental data; more than to validate the numerical model, these comparisons could drive the attention of modelers to issues of future research. The development of a numerical model as the one here described depends on the availability of a robust experimental dataset, firstly for representing the rheological behavior of the liquid product, secondly for identifying parameters for the relevant thermal boundary conditions. It is strongly recommended that the datasets should include a larger selection of heat treatments, as well as a larger selection of temperatures for measurement of the liquid product viscosity after every heat treatment.

Future efforts should be devoted to the detailed representation of aggregation processes, including interactions between whey proteins and the major other species contained in the liquid product.

\section{Acknowledgements}

The research leading to these results has received funding from the European Community's Seventh Framework Program (FP7/2007-2013) un- der the grant agreement number FP7-222 654DREAM. Authors acknowledge the COMSOL support team for the kind assistance.

\section{References}

Aguiar, H. F., \& Gut, J. A. W. (2014). Continuous htst pasteurization of liquid foods with plate heat exchangers: Mathematical modeling and experimental validation using a time-temperature integrator. Journal of Food Engineering, 123, 78-86. doi:10 . 1016/j.jfoodeng.2013.09.022

Amestoy, P. R., Duff, I. S., L'Excellent, J. Y., \& Koster, J. (2001). A fully asynchronous multifrontal solver using distributed dynamic scheduling. Siam Journal on Matrix Analysis and Applications, 23(1), 15-41. doi:10.1137/S0895479899358194

Bird, R. B., Stewart, W. E., \& Lightfoot, E. N. (2007). Transport phenomena (revised second ed.) john wiley \& sons. New York.

Brodkey, R. S., Lee, J., \& Chase, R. C. (1961). A generalized velocity distribution for nonnewtonian fluids. Aiche Journal, 7(3), 392393. doi:10.1002/aic.690070309

Chantoiseau, E., Plana-Fattori, A., Doursat, C., \& Flick, D. (2012). Coupling fluid flow, heat transfer and thermal denaturationaggregation of beta-lactoglobulin using an eulerian/lagrangian approach. Journal of Food Engineering, 113(2), 234-244. doi:10. 1016/j.jfoodeng.2012.05.043

Chhabra, R. P. (1999). Heat and mass transfer in rheologically complex systems. In Rheology series (Vol. 8, pp. 1435-1488). Elsevier.

Coutouly, A., Riaublanc, A., Axelos, M., \& Gaucher, I. (2014). Effect of heat treatment, final ph of acidification, and homogenization pressure on the texture properties of cream cheese. Dairy Science \& Technology, 94(2), 125-144. doi:10.1007/s13594013-0148-z

Datta, A. K. (2008). Status of physics-based models in the design of food products, processes, and equipment. Comprehensive Reviews in Food Science and Food Safety, 7(1), 121-129. 12 World Congress of Food Science and Technology, Chicago, IL, JUL 
16-20, 2003. doi:10.1111/j.1541-4337.2007. 00030.x

Goode, K. R., Asteriadou, K., Robbins, P. T., \& Fryer, P. J. (2013). Fouling and cleaning studies in the food and beverage industry classified by cleaning type. Comprehensive Reviews in Food Science and Food Safety, 12(2), 121-143. doi:10.1111/1541-4337. 12000

Khaldi, M., Croguennec, T., Andre, C., Ronse, G., Jimenez, M., Bellayer, S., ... Delaplace, G. (2018). Effect of the calcium/protein molar ratio on betalactoglobulin denaturation kinetics and fouling phenomena. International Dairy Journal, 78, 1-10. doi:10.1016/j.idairyj . 2017.10.002

Kumar, V., Aggarwal, M., \& Nigam, K. D. P. (2006). Mixing in curved tubes. Chemical Engineering Science, 61(17), 5742-5753. doi:10.1016/j.ces.2006.04.040

Lalande, M., Tissier, J. P., \& Corrieu, G. (1985). Fouling of heat-transfer surfaces related to beta-lactoglobulin denaturation during heat processing of milk. Biotechnology Progress, 1(2), 131-139. doi:10.1002/ btpr. 5420010210

Li, L., Singh, R. K., \& Lee, J. H. (2004). Process conditions influence on characteristics of holding tube fouling due to cheese sauce. Lebensmittel-Wissenschaft Und-Technologie-Food Science and Technology, 37(5), 565-572. doi:10.1016/j.lwt. 2004.01.002

Luna, N., Méndez, F., \& Treviño, C. (2002). Conjugated heat transfer in circular ducts with a power-law laminar convection fluid flow. International Journal of Heat and Mass Transfer, 45(3), 655-666. doi:10.1016/ S0017-9310(01)00147-8

Lyster, R. L. J. (1970). The denaturation of alpha-lactalbumin and beta-lactoglobulin in heated milk. Journal of Dairy Research, $37(2), 233-243$.

Ndoye, F. T., Erabit, N., Alvarez, G., \& Flick, D. (2012). Influence of whey protein aggregation on the residence time distribution in a tubular heat exchanger and a helical holding tube during heat treatment process. Journal of Food Engineering, 112(3),
158-167. doi:10.1016/j.jfoodeng.2012.03. 036

Pepper, D. W., Kassab, A. J., \& Divo, E. A. (2014). An introduction to finite element, boundary element, and meshless methods with applications to heat transfer and fluid flow. American Society Of Mechanical Engineers.

Petit, J., Herbig, A.-L., Moreau, A., \& Delaplace, G. (2011). Influence of calcium on betalactoglobulin denaturation kinetics: Implications in unfolding and aggregation mechanisms. Journal of Dairy Science, 94(12), 5794-5810. doi:10.3168/jds.2011-4470

Plana-Fattori, A., Chantoiseau, E., Doursat, C., \& Flick, D. (2013). An eulerian-lagrangian approach for coupling fluid flow, heat transfer and liquid food product transformation. Computers \& Chemical Engineering, 52, 286-298. doi:10.1016/j.compchemeng. 2013.01.020

Ramaswamy, H. S., Abdelrahim, K. A., Simpson, B. K., \& Smith, J. P. (1995). Residence time distribution ( $\mathrm{rtd}$ ) in aseptic processing of particulate foods - a review. Food Research International, 28(3), 291310. doi:10.1016/0963-9969(95)00005-7

Swaisgood, H. E. (1995). Protein and amino acid composition of bovine milk. In Handbook of milk composition (pp. 464-468). Elsevier.

Tolkach, A., \& Kulozik, U. (2007). Reaction kinetic pathway of reversible and irreversible thermal denaturation of betalactoglobulin. LAIT, 87(4-5), 301-315. 27th World Dairy Congress and World Dairy Summit of the InternationalDairy-Federation, Shanghai, PEOPLES R CHINA, OCT 18-23, 2006. doi:10.1051/lait:2007012

van Boekel, M., Fogliano, V., Pellegrini, N., Stanton, C., Scholz, G., Lalljie, S., ... Eisenbrand, G. (2010). A review on the beneficial aspects of food processing. Molecular Nutrition \&6 Food Research, 54(9), 12151247. doi:10.1002/mnfr.200900608

Vashisth, S., Kumar, V., \& Nigam, K. D. P. (2008). A review on the potential applications of curved geometries in process industry. Industrial \& Engineering Chemistry 
Numerical modelling of thermal denaturation-aggregation | SI37

Research, 47(10), 3291-3337. doi:10.1021/ ie701760h

White, F. M., \& Corfield, I. (2006). Viscous fluid flow. McGraw-Hill New York.

Zimmerman, W. B. J. (2006). Multiphysics modeling with finite element methods. World Scientific Publishing Company. 